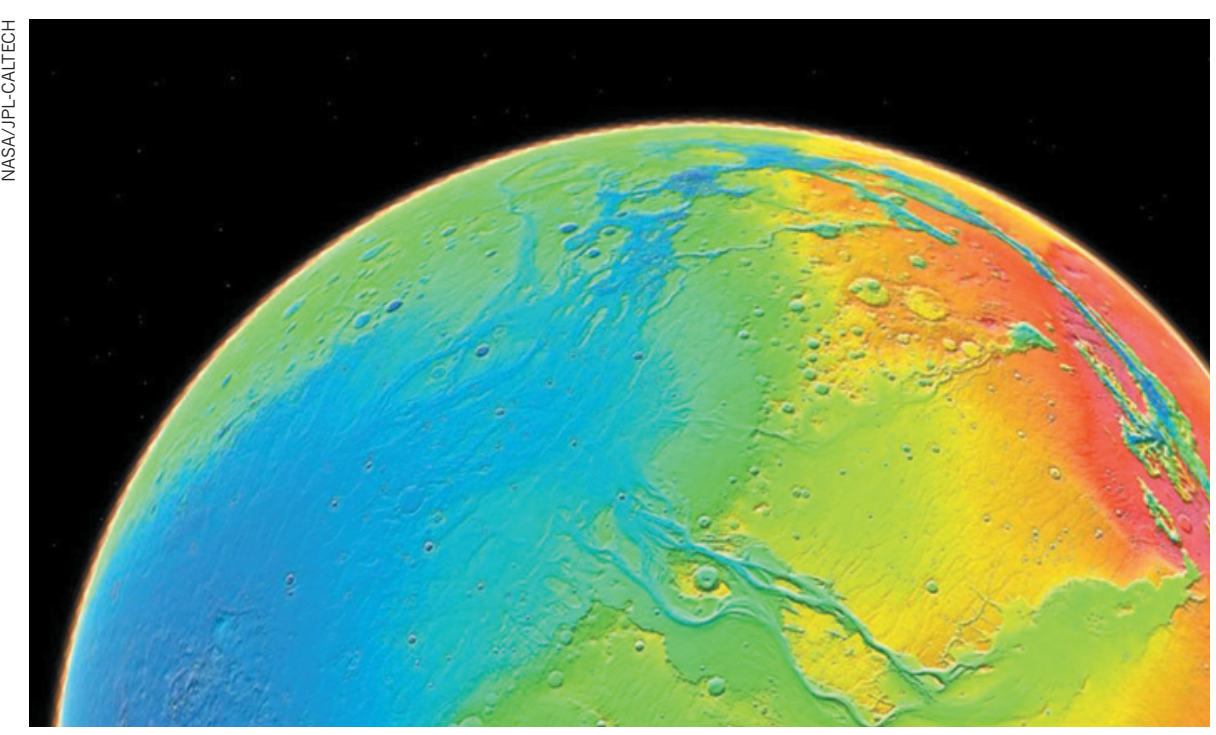

Sea change: previous ideas that lowlands on Mars (blue) once hosted oceans are being overturned.

\title{
ASTRONOMY
}

\section{Dreams of water on Mars evaporate}

\section{Climate models reveal the red planet was mostly cold and dry.}

\section{BY ERIC HAND}

$\mathrm{T}$ he debate began when nineteenthcentury Italian astronomer Giovanni Schiaparelli thought he saw waterfilled canali, or channels, on the red planet: just how wet was Mars? "This is a pendulum that has been swinging back and forth," says Jeff Andrews-Hanna, a planetary scientist at the Colorado School of Mines in Golden. The canali were an illusion, and no one doubts that Mars today is dry except for possible meagre seeps of groundwater. But in recent years researchers have come to accept that ancient Mars had lakes or even oceans - favourable conditions for life. "This is what started off the fever for Mars science," Andrews-Hanna says.

But the pendulum is swinging again. Last month, Jim Head, a planetary scientist at Brown University in Providence, Rhode Island, threw a wet blanket on the idea that Mars was ever very wet at all, in a keynote talk at the Lunar and Planetary Science Conference in The Woodlands, Texas. Head and others are assembling a picture of a Mars that was cold and dry from the beginning, punctuated at most by short bursts of wetness. "The notion of a palm-tree-covered Mars has waned," says Stephen Clifford, a planetary scientist at the Lunar and Planetary Institute in Houston, Texas, who is organizing a conference in May on the early climate of Mars.
The first spacecraft to visit Mars, in the 1960s and 1970s, showed a bone-dry planet pocked with craters, much like the Moon. But high-resolution cameras on orbiting missions such as the Mars Global Surveyor, which launched in 1997, showed valley networks braided and branched channels about 3.7 billion years old that seemed to have been carved by water. Then in 2005, a spectrometer on the Mars Express satellite found widespread evidence for clays ${ }^{1}-$ minerals that testify to hundreds or even thousands of years of exposure to water. Suddenly, geologists did not seem so bold in tracing out the palaeo-shorelines of an ocean that could have covered the planet's entire low-lying northern hemisphere.

But Head and others have countered that view with three main lines of evidence. The first comes from models of the ancient Martian climate that fail to predict temperatures high enough for rain, or for liquid water to persist on the surface at all. The young Sun was fainter than it is today, and even if the young Mars had a thicker atmosphere, its greenhouse effect would probably not have warmed the planet above freezing, says François Forget at the University of Paris. He has submitted to the journal Icarus what he says is the most sophisticated three-dimensional

\section{$\rightarrow$ NATURE.COM}

For more on the red planet, see:

go.nature.com/lizth3 climate model for Mars so far. It predicts that any water on Mars would have been bound as ice at higher elevations.

By next month's conference, Forget hopes to incorporate the effect of greenhouse gases, such as sulphur dioxide, that could have been present occasionally in huge doses. He hopes to test the idea, proposed by Head, that sulphurous bouts of volcanic activity could have warmed the atmosphere for brief periods, just enough to melt the icy highlands and unleash torrents that could have carved the valley networks. Other researchers invoke local melting from the heat from large asteroid impacts.

Closer inspection of the valley networks supports the sporadic presence of water rather than an enduring wet climate, Head says. He points to studies, including his own, showing that some of the networks are isolated geographically and in time, having formed hundreds of millions of years apart ${ }^{2}$.

Even the clay minerals may not support a wet planet. A team using a spectrometer on the Mars Reconnaissance Orbiter found that roughly $80 \%$ of the clays occur together with other minerals that form at relatively high temperatures. This suggests that the clays formed not in cool surface water but underground, in water warmed by leftover heat from Mars's formation, says Bethany Ehlmann, a planetary scientist at the California Institute of Technology in Pasadena, who led the study ${ }^{3}$.

Curiosity, the NASA rover that is expected to land on 5 August, may get a closer look. A thin ring of clay encircles a 5-kilometre-high mound in the middle of the Gale crater, where the rover will touch down. Although Ehlmann says that these clays are probably among the $20 \%$ that formed with surface water, their textures will reveal something about the extent of that water. Were the clays deposited in a persistent, deep lake? Or could the waters have been shallow and short-lived? Some geologists have even suggested that the minerals could have formed in the presence of ice.

Andrews-Hanna says the shift in thinking doesn't rule out life on ancient Mars, but instead drives it deeper underground. "If Mars's climate was never stable, that would have been a challenge for life," he says. "But as you go deeper in the subsurface, things become more stable."

Head doesn't think his revisionism causes too many problems for ancient life even at the surface. He says ancient Mars could have been very much like the dry valleys and ephemeral lakes of Antarctica, where dried-up mats of algae bloom in the warmer season, nourished by a trickle of meltwater from the icy highlands above. "The public perception is that warm and wet equals life," he says. "If you look at the range of life on Earth, there's no reason to suspect that life is limited to that." -
1. Poulet, F. et al. Nature 438, 623-627 (2005).

2. Fassett, C. I. \& Head, J. W. III Icarus 195, 61-89 (2008).

3. Ehlmann, B. L et al. Nature 479, 53-60 (2011). 